\title{
Local residents' sense of autonomy towards marine-based adventure tourism development in Ambon
}

\author{
Muhammad Rizali Umarella, Muhammad Baiquni, Sigit Heru Murti, and Muh Aris Marfai* \\ Faculty of Geography, Universitas Gadjah Mada, Yogyakarta, Indonesia
}

\begin{abstract}
Marine-based adventure tourism is one of the fastest growing areas within the world's largest industry. Regardless the increasing awareness of the economic and environmental significance of adventure marine-based tourism, it is only in recent years that a substantial body of research has developed but mostly still focuses only in the area of the visitors. Meanwhile, the local residents as an important factor who take role in the establishment of adventure marine-based tourism development has little been studied. Therefore, the local residents' sense of autonomy in developing the marine-based adventure tourism in Ambon was examined by means of qualitative interview study. Data has been collected through semi-structured interviews and field observations. Furthermore, the data has been analysed by inductive analysis. Series of focus group discussions and participatory GIS have been done in order to enrich the data collection process The findings of this study which are three major emergent themes, serve as a basis for the local residents to develop marine-based adventure tourism in a sustainable approach. Their sense of autonomy along with the stakeholders in developing the marine-based adventure tourism will result in more benefits for the visitors as well as the local economy development.
\end{abstract}

Keywords: marine-based adventure tourism, local community, participation, Ambon.

\section{Introduction}

Indonesia is the largest archipelago in the world encompassing thousands of tropical islands along with its sandy beaches. One of the high potential resources in an archipelago is the tourism sector [1]. Tourism becomes the most admired industries and has been growing rapidly in many developing countries. Tourism as a union of activities, services and industries offers a notable experience by combining accommodation, transportation, attraction, vending, and destination marketing. These activities require goods and services which in exchange do and can provide economic benefits for not only businesses involved therein but also for destinations such as Molucca Island, and Ambon in particular.

Coastal area and marine environment are the most dynamic area with many land use, purposes, including aquacultures, industries, and tourism [2]. The marine environment is still attractive for tourists and goes beyond just ordinary its sea-sand-sun. The marine environment is a complex system which becomes more noticeable as an open space for adventure tourism, which provide tourists with the feeling of accomplishing the challenges. This marine-based adventure tourism suits well with the geomorphological characteristics of Ambon.

The development of marine-based adventure tourism along with its local residents' support, have generated diverse literature in recent years by many experts [3-5]. Local residents as an important subject involved in the development of marine-based adventure tourism very often tend to be neglected. The focus is usually on gaining the maximum number of visitors instead of strengtening the local residents so they are autonomous in developing this tourism.

Self-Determination Theory (SDT) accounts for the marine-based adventure tourism experiences in terms of their ability to fulfill the local residents' intrinsic motivation-autonomy, competence, and relatedness needs - ultimately enhancing perceived satisfaction of the tourism development activity [6-8]. Out of these kinds of intrinsic motivation, autonomy is the most relevant to the local residents in developing the marinebased adventure tourism because the feeling is directly linked to the freedom to make choices.

Human beings, naturally, always try to make their own decisions, fulfill their own goals, and come up with their own thoughts. In other words, they want to be autonomous. Based on SDT, [9], which is a broad theory of human motivation and personality, autonomy is one of the three basic psychological needs which are necessary for optimal growth and well-being. When the feeling of autonomy exists, they recognize their needs, motivations, preferences and behaviors to be aligned and congruent with one another. In other words, they feel like the directors of their own lives and live according to their own interests and values.

Community based tourism (CBT) focuses on the involvement of the local community in planning and maintaining tourism development in order to create a more sustainable industry [10]. The tourism industry depends on local resident involvement, through their role as employees or local entrepreneurs, and on resident goodwill towards tourists $[11,12]$. However, most of the literature suggests that tourism will be more successful if local residents are supportive $[12,13]$.

A various range of studies on the impacts of tourism development on local communities has been conducted over the last decade $[14,15]$. The destination's

\footnotetext{
* Corresponding author:arismarfai@ugm.ac.id
} 
attractions and other supporting factors within the communities determine the success of local tourism. Other significant factor is also the efficient local management, whether it is to reduce the negative impacts or the costs of development, or its beneficial management so these benefits can be allocated appropriately and among local residents. Sustainable development of tourism will be achieved by applying proper management of such impacts. Not only can the impacts will affect local residents' but also they can directly influence the support for tourism development within the community [15].

A number of studies have discussed the intrinsic motivation factors based on tourists' perspective, such as intrinsic motivation in the involvement in adventure tourism activities and accomplishment [16]. Nevertheless, a few studies investigated these factors from local perspectives and the way intrinsic motivation factors motivate them to support tourism development.

There is no commonly accepted definition over the last two decades on autonomy in tourism. The most mentioned theory relating about autonomy derives from [9] in which they proposed three main intrinsic needs involved in self-determination. These three needs motivate the self to initiate behaviour and specify nutriments that are essential for psychological health and well-being of an individual. These needs are said to be universal, innate and psychological, and include the need for competence autonomy and relatedness. Autonomy refers to to actions that are self-endorsed and based on one's integrated values or interests. In attributional factor, autonomous actions have internal receives locus of causality; the phenomenal emanating from the self [17]. Autonomy in a person is described as growth and the crises of ones, as a series of alternative basic attitudes in doing things autonomously. Various activities of a person should come a comfortable sense of autonomy and of being a capable worthy person [18].

The definitions of tourism vary across different fields. Based on the aim of this paper, the primary element is that tourism becomes the business of trading adventurous opportunities for economic gain along with its complexity. The marine environment is the essential element to be uniquely developed by the local residents.

This paper discusses the local residents' sense of autonomy in search of developing marine basedadventure tourism. It presents a brief overview of the nature of adventure tourism in marine environment and of resources for providing such uses. The objective is to address the question of how marine-based adventure tourism can be developed autonomously by the local residents along together with the stakeholders in Ambon.

\section{Methods}

This study is based on semi-structured in-depth interviews, a method suitable for inductively examining people's review regarding a phenomenon [19]. Furthermore, [20] groups qualitative methods into three broad types: in-depth interviews with groups and individuals; direct engagement with subjects through participant observation and related ethnographic techniques; and the interpretation of a variety of 'texts' including landscapes, archival materials (e.g., memo, diaries), maps and visual images. Participant observation has been done in a way of living and staying together within the community. The first author originally from neighbourhood area and had opportunity to do participant observation in a short time before during and after focus group discussion as well as in the long duration in daily live activities from August 2019March 2020.

Based on the research construct on adventure tourism development that underlays this research, the interview questions were grouped in 3 categories. The participants were asked to describe (1) the awareness of the local residents on the potentiality of the marinebased adventure tourism development in their area, (2) their involvement with the stakeholders in development of this marine-based adventure tourism, (3) the creation of the local residents on the marine-based adventure tourism development. To enrich the data collection process and maintain its validity of the qualitative data, each interview was followed by a number of focus group discussions in which the process of participatory GIS was also accomplished. Focus group discussion allows us to confirm, recheck, and strengthen the qualitative data of interview.

The interviews and the focus group discussions were conducted between August 2019 to March 2020 in Ambon (Figure 1; Table 1). The sample consisted of 25 persons, selected according to the theoretical sampling approach applied in the grounded theory [21] due to grounded theory's conception as a more "objective" way of doing qualitative inquiry in tourism [22]. The objective of this procedure is not to get statistical representativeness, but to maximize the variability of opinions and perspectives expressed.

The analysis of this study is in the light of inductive analysis of Grounded Theory which involves discovering patterns, themes, and categories in one's data $[23,24]$. The main variables according to which members of the 2 groups (local residents and other stakeholders) were selected, were age, occupation, gender, and place of residence (presented in Table 2).

The purpose of grounded theory is to build theories from data about the social world such that theories are "grounded" in people's everyday experiences and actions [25]. The methods of grounded theory are iterative, reflexive, and inductive; that is, they involve multiple stages of collecting data, coding, and analyzing them, reflecting on emerging themes, collecting more data targeted to initial theories, and constantly comparing the insights that evolve. Grounded theory operates at both concrete and abstract levels as it seeks both to represent concrete situations in their complexity and to produce abstract theory.

Grounded theory has a basic compatibility with GIS in that it enables or demands attention to both the particular and the general. Further, grounded theory provides strong potential for much of the current work in critical geography through its central focus on subjectivity, difference, meanings, discourse, partial or situated knowledge, and power, as well as being open to 
geographical concerns of scale, place, content, and flows $[26,27]$.

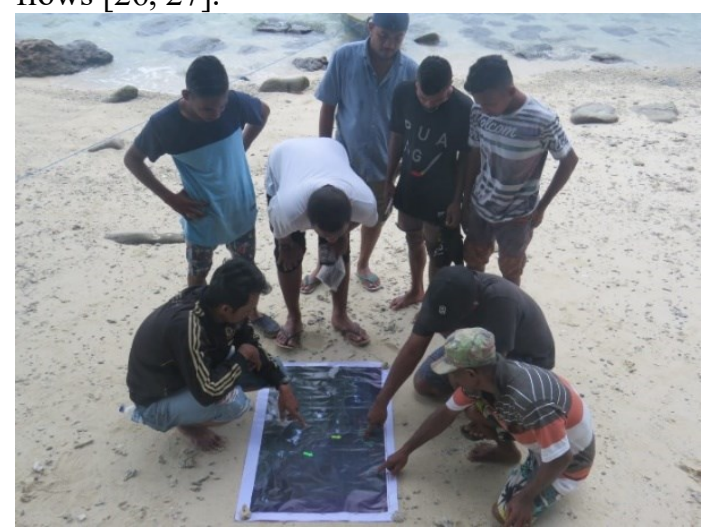

Fig. 1. Focus group discussion with local residents

Table 1. The Geographical Description of Ambon Island (Source: Badan Pusat Statistik Provinsi Maluku)

\begin{tabular}{|l|l|}
\hline \multicolumn{2}{|c|}{$\begin{array}{c}\text { The Geographical description of Ambon } \\
\text { Island }\end{array}$} \\
\hline Total area & $803,9 \mathrm{~km}^{2}$ \\
\hline Total area of the study & $220 \mathrm{~km}^{2}$ \\
\hline Altitude & $0-500 \mathrm{~m}$ \\
\hline Inhabitants in 2015 & $1,831,880$ \\
\hline $\begin{array}{l}\text { Variation of coastal wave } \\
\text { height }\end{array}$ & $1-6 \mathrm{~m}$ \\
\hline
\end{tabular}

Table 2. Profile of participants

\begin{tabular}{|c|c|c|c|c|}
\hline No. & Sex & Age & Occupation & $\begin{array}{c}\text { Residential } \\
\text { status }\end{array}$ \\
\hline 1. & $\mathrm{M}$ & 47 & Public worker & \multirow{25}{*}{$\begin{array}{l}\text { Long- } \\
\text { established } \\
\text { (Since } \\
\text { birth) }\end{array}$} \\
\hline 2. & $\mathrm{M}$ & 40 & Local guide & \\
\hline 3. & $\mathrm{M}$ & 38 & Local guide & \\
\hline 4. & $\mathrm{~F}$ & 46 & Home/commerce & \\
\hline 5. & $\mathrm{M}$ & 51 & Fisherman & \\
\hline 6. & $\mathrm{M}$ & 36 & $\begin{array}{l}\text { Driver (private } \\
\text { transport) }\end{array}$ & \\
\hline 7. & $\mathrm{~F}$ & 42 & Home/commerce & \\
\hline 8. & $F$ & 37 & $\begin{array}{c}\text { Local culinary } \\
\text { cook }\end{array}$ & \\
\hline 9. & $\mathrm{M}$ & 41 & Local guide & \\
\hline 10. & $\mathrm{M}$ & 55 & Fisherman & \\
\hline 11. & $\mathrm{M}$ & 46 & $\begin{array}{l}\text { Driver (private } \\
\text { transport) }\end{array}$ & \\
\hline 12. & $\mathrm{M}$ & 49 & $\begin{array}{l}\text { Marine-based } \\
\text { commerce }\end{array}$ & \\
\hline 13. & $\mathrm{M}$ & 44 & Fisherman & \\
\hline 14. & $\mathrm{~F}$ & 40 & $\begin{array}{c}\text { Local culinary } \\
\text { cook }\end{array}$ & \\
\hline 15. & $\mathrm{M}$ & 53 & $\begin{array}{l}\text { Marine-based } \\
\text { commerce }\end{array}$ & \\
\hline 16. & $\mathrm{M}$ & 39 & Public worker & \\
\hline 17. & $\mathrm{M}$ & 42 & Fisherman & \\
\hline 18. & $\mathrm{M}$ & 44 & $\begin{array}{c}\text { Marine-based } \\
\text { commerce }\end{array}$ & \\
\hline 19. & $\mathrm{M}$ & 48 & Local guide & \\
\hline 20. & $\mathrm{M}$ & 42 & Public worker & \\
\hline 21. & $\mathrm{~F}$ & 39 & $\begin{array}{c}\text { Local culinary } \\
\text { cook }\end{array}$ & \\
\hline 22. & $\mathrm{M}$ & 36 & Fisherman & \\
\hline 23. & $\mathrm{M}$ & 41 & Fisherman & \\
\hline 24. & $\mathrm{M}$ & 45 & Public worker & \\
\hline 25. & $\mathrm{~F}$ & 53 & Home/commerce & \\
\hline
\end{tabular}

The contents of the transliterated interviews and the focus groups were analyzed using the Grounded Theory approach according to Glaser and Strauss [21. Grounded theory involves the collection, coding, and categorization of qualitative data (transcribed text from interviews, focus groups, and researchers' notes, photographs, and other images) towards enabling themes to emerge through iterations of "constant comparison". Geographers have recently begun to pay more attention in grounded theory as a qualitative methodology, adopting it from its roots in sociology [28]. The first step in data analysis began in reading of every single interview text and the focus group transcription texts. The next step was to allocate appropriate thematic codes to short passages (open coding). Based on the concept map used in this qualitative study, the themes and patterns of both types of texts were carried out using visual identification. It was the linkage that facilitated the process of understanding interconnections and meanings of data. After coding process had been completed, the next analysis was to develop sub-themes and emergent themes in order to be able to understand the phenomena.

\section{Result and discussion}

The interview and focus group analysis resulted in a large variety and complex interplay concepts relevant to the respondents' sense of autonomy. There were 25 participants involved in this study, all of whom were long-established residents, meaning that they have lived in the study area since birth. These local residents shared experience in the marine-based adventure tourism development under the construct of sense of autonomy, during in-depth interviews, focus groups, other informal interviews.

Each participant told story (interview texts and focus groups) of their unique experience of this phenomenon, and described the meaning that they attributed at this experience. This is an example of the script of the interview data:

"Au lahir nala au nela wa eike, pahai wa meit tatutu kakekare, turu iskola, pahai bale, meit tatutu ahanau au rumah eya. Mansia riahahai isi lai waeike, hatuai sanang isi pahoi meite, umalaing puti nanae, isi pahai tawai waeike" ("I was born and grew up here. When I was a kid, the beach was used to be my playground and a perfect place for playing mini soccer game. This beach is my home. For the tourists who came here, they felt this homey feeling, enjoying the sea water and the beach, whole day long, no rush").

This individual story and the whole data aims at to fully demonstrate the meanings that emerged through thematic analysis of the shared experience. Three main themes relating to these local residents' experiences emerged from the data, and each of these themes reveals how they made meaning of their sense of autonomy experience in the marine-based adventure tourism development (Table 3). 
Table 3. Emergent themes and sub-themes of the local residents' sense of autonomy in the development of marinebased adventure tourism

\begin{tabular}{|c|cl|}
\hline \multicolumn{1}{|c|}{ Themes } & & Sub-Themes \\
\hline Space Creations & - & Assessing oneself \\
& - & Initiating contribution \\
& - & Technology support \\
\hline Thoughtfulness & - & Self-organized attempt \\
& - & $\begin{array}{l}\text { Stakeholders } \\
\text { collaboration }\end{array}$ \\
\hline Reconstructions & - & $\begin{array}{l}\text { Reflecting on one's } \\
\text { experience } \\
\text { Developing critical } \\
\text { consciousness }\end{array}$ \\
\hline
\end{tabular}

\section{Interpretation of the findings}

This study discusses the lived experience of the local residents' sense of autonomy in developing marinebased adventure tourism in Ambon and tries to make meaning of the lived experience by them. Data interpretation deals with the meaning made of the data and how it has been translated through the process into findings based on phenomenology approach.

\subsection{Space creation}

Space creations relate to the marine environment in a life span of local residents' experience since they were born. Each local resident autonomously creates his/her space in developing something. Space creation in this case involves the ability to realize that their living surrounding environment has many potentials to be included in the planning process of development. In the effective tourism planning, the local residents' awareness and involvement are required as the experts and practitioners recommend. In return for mitigating impacts and clarifying benefits, tourism planners can earn residents' support for tourism initiatives and create a favourable attitude [29]. Besides that, the local residents' attitudes are important for their support for tourism in the destination. It is difficult to develop tourism sustainability in the destination without the participation and support of residents [30-33].

The sub-themes, namely, assessing oneself, initiating contribution, and technology support, are woven together. Assessing oneself was part of the space creations in the sense that these local residents have come to realize that they are surrounded by precious resources that are waiting to be developed and sustainably managed. This self-assessment comes from their internal motivation which refers to engagement in an activity because of the inherent pleasures and satisfactions it provides. Many actions are carried out because of the feeling of enjoyment in their own right, and require no exogenous rewards or incentives to be performed [9]. In contrast, extrinsic motivation characterizes actions that are performed in order to obtain separable outcome, whether that be a tangible reward, and avoidance of a punishment, or the attainment of recognition, or approval. Because the determinants and consequences of intrinsic and extrinsic motivation differ, this paper will only discuss the intrinsic motivation as it covers the sense of autonomy.

Once they are able to identify their own space of the tourism development, they create spaces to start contribute in this development process which in fact lead them to be the central in the process. As the advancement of technology has reached Ambon island, the local residents create their cyberspace learning in attempt to be able to update knowledge about the planning of development process. Consequently, these conscious experiences of autonomous became the space creation. When autonomous, people endorse their own feelings and actions at the highest order of reflection [34]. This aspiration to feel self-directed and selfendorsed is innate. Naturally, every individual will attempt to have this need fulfilled, as long as their environmnt facilitates and supports this attempt. This implies that the individual is continually involved in an interaction with his or her environment, and while the need for autonomy is present in all individuals regardless of background or culture [16], it requires nutrients from the environment in order to flourish.

Based on the texts of the local residents, the experience of feeling taking the environment for granted, creates an image of no need to develop this environment further. This image represents a dialog between the researcher and the text [28].

\subsection{Thoughtfulness}

In this theme, thoughtfulness, three sub themes were developed from the data. The first sub-theme involved giving more meaning in the development process of marine-based adventure tourism. These three subthemes need to be elaborated in order to get deeper understanding of the phenomena. This theme disclosed how the local residents experienced their involvement in a day-to-day world in Ambon Island. It is a world of sharing and cooperativeness that sprinkle the feeling of thoughtfulness in all development process. For the local residents, their experience in developing marine-based adventure tourism involves thought and showing more consideration than before. These local residents give more meaning to the marine-based adventure tourism by using maps in the focus group discussions in order to increase their excitement. When it came to self-chosen topic about marine-based adventure development, these local residents were highly motivated in being involved in the development process. Autonomous motivation occurs when individuals identify with the value in the activity, and integrate that value into their own sense of self [35]. Individuals in this category experience volition, self-control and/or self-endorsement in their decision to participate in an activity [35].

The opportunities to make choices that the local residents have, provide them with a variety of route that will lead them to the same destination; a successful marine-based adventure tourism development which brings economically benefits for them. In fact, the marine environment allows these local residents, either individually or as a group, to explore those routes and finally each of them become self-organized to reach their common goal. The intention of reaching the 
common goal comes from intrinsic motivation where all the drives are brought into reality. Intrinsic motivation factors, in much the same way as other determinants of support for tourism development also affect the way that locals perceive tourism impact [36]. As an important intrinsic psychological factor associated with an individual resident, non-monetary gains may play an important role in forming a residents' attitude towards tourism development. Psychologically, by developing tourism projects in rural and remote areas, local people seek non-monetary gains when they evaluate the exchange to support the industry [36].

In addition, the idea of being-in-the-world or the well-being of a human, being familiar with independency [37], helped the participants to appreciate others in terms of the interests in developing marinebased adventure tourism. Being in state of independency which lead to group independency increased consciousness for extending the development process until shared understanding was achieved.

There were some occasions when self-organized actions were practiced into groups. The local residents described many situations when they felt they had to take action together in order to achieve better results. For example, during the in-depths interviews and focus group discussions, a number of local residents recalled that when the local stakeholders were not able to help them financially to set up new facilities for the tourists such as renew the wooden bridge for diving start point, these local residents solved out the problems by sharing the tasks of providing the materials and then worked together to make those facilities. This choice of action along with the control over what they can do to contribute to the marine-based tourism development enhance a sense of autonomy and minimize the weakening of perceived autonomy $[9,38]$.

\subsection{Reconstruction}

This theme is the final emergent theme among the three themes emerged from the study. This theme merged from two sub-themes, namely reflecting on one's experience and developing critical consciousness. The local residents' sense of autonomy experience was observed during the gradual flow of thought in the data processing process. This third theme becomes the continuum which the other themes, space creations and thoughtfulness, move along. Reconstruction is the milestone for any local residents during their process of developing marine-based adventure tourism. There is no intellectual growth without some reconstructions, some reworking [39]. It is the stage when the local residents reconstruct their experiences from bits and pieces about past events and current situations, and later weave in bits and pieces of detail to develop a coherent story. It is about retaining experience of these local residents' sense of autonomy in developing marine-based adventure tourism for a period of time. Definition of this autonomous motivation has been associated with greater persistence, more positive effect, enhaced performance, and greater psychological well-being. Using the constructs with SDT, autonomous motivation is comprised of identified regulation and integrated regulation, two forms of extrinsic motivation, as well as intrinsic motivation [35].

The first sub-theme, reflection on one's experience, acts as a bridge to the other sub-themes within the framework of constructivist approach. The action of constructivism is another base which indicates that all efforts of marine-based adventure tourism in Ambon involves relearning, reorganization, in one's prior presentation of the world. Each local resident in this study constructs their own way of thinking and learning new things that they are active explorers who are constructing a mental model of how they marine-based adventure tourism development fits harmoniously in their daily life. These local residents' experience in reflecting back on what they have experienced in the past and bring forward the actual action for the sake their communal development as well. One of the local resident participated in this study, for example, set up an informal afternoon sharing session at the communal coffee shop and brought up the topic of how tourism can elevate their economy status. Other local resident in this study agreed with this idea while he also proposed to include new knowledge on this development process, although he still tried to think critically to get maximum effort to do so.

In this matter, there are some main aspects of intrinsic motivation factors for support of tourism development, such as opportunities to be a host to guests, an opportunity to create a relationship, to play a role, the feeling of being needed, to work together as a community and gain self-respect [36]. Developing critical consciousness are achieved by these local residents, meaning that they have the ability to recognize the conditions that result in privileging of one idea over another within a particular culture or society [40].

\section{Conclusion}

This study examined the lived experience of the local residents' sense of autonomy in developing and managing the strategies. There are three major emergent themes, namely space creation (experience of the participants creating their planning and development space), thoughtfulness (their learning space about marine-based development inside the world of sharing and cooperativeness), reconstructions (the milestone of their enhancement performance to achieve the most desirable goal and pursue a good collaboration with all the stakeholders).

From these findings, the following main conclusion regarding the initial objective can be ascribed to the local residents' sense of autonomy. Even if the conclusions drawn from this study are based on research in one particular study area, they may be applicable to other coastal places with similar geographic and sosioeconomic charachteristics. Thus, striking a balance between appropriate economic development through marine-based adventure tourism desired by the locals residents and the support from local stakeholers is the challenge for sustainable development that aims to meet 
the needs and aims of both groups. To reach ths goal, more research is needed.

Thanks to community leaders (Head of Tourism Bureau of Maluku Province, The Rajas, and POKDARWIS of the study area) and local government for their support during the field observation. Part of this research has been supported by hibah collaboration (Hibah PPKI 2020).

\section{References}

1. M. Baiquini, J. Damanik, E. Rindrasih, Ecotourism Destinations in Archipelago Countries, Yogyakarta: GMUP (2014). (1)

2. Muh Aris. Marfai. Quaest. Geogr. 33,1:107-114 (2014).

3. M. Orams, Marine Tourism: Development. Impacts and Management. London: Routledge. (1999).

4. R.R. Perdue. P.T. Long. Allen. J. Travel Res. 28,3:3-9 (1990).

5. S. Smith, Qualitative methods, In: The Dictionary in Human Geography. Blackwell: Oxford, p. 660662. (2000).

6. T. Aicher, J. Brenner, IJSMaRT, 18(d), 56-81 (2015).

7. S.P. Cottrel, J. Vaske, J. Roemer, JTMP. 8:42-48 (2013).

8. D. Kala, S. Bagri, Tourism. 66,3:318-333 (2018).

9. R. Ryan, E. Deci, Am. Psychol. 55,1:68-78 (2000).

10. C.M. Hall, Introduction to Tourism in Australia: Impacts. Planning. and Development. Melbourne: Addison. Wesley. and Longman (1996).

11. K. Blackstock, Community Dev. J., 40,1:39-49 (2005).

12. E. Laws, Tourist Destination Management: Issues. Analysis and Policies. NY: Routledge (1995).

13. L.P. Rhonda. H.L. Raynald. Tour. Geogr., 11,2: 256-269 (2009).

14. S. Akis, N. Peristianis, J. Warner, Tour. Manag., 17,7:481-494 (1996).

15. P. Dyer, D. Gursoy. B. Sharma. J. Carter. Tour. Manag. 28,2:409-422 (2007).

16. A. Correia, Metin, K. J. Ferradeira, IJCTHR.7,4:411-424 (2013).

17. V.L. Chirkov, R.M. Ryan, J. Cross Cult Psychol., 32,5:618-635 (2001).

18. E.H. Erikson, The life cycle completed: A review. NY: W.W. Norton. (1982).

19. B.L. Berg, Qualitative Research Methods for the Social Sciences, Needham Heights: Allyn \& Bacon (2001).

20. A. Strauss, J. Corbin, Basics of qualitative research: Techniques and procedures for developing grounded theory $2^{\text {nd }}$ ed. Cal: Sage. (1998).

21. B.G. Glaser, A.L. Strauss, The discovery of grounded theory: strategies for qualitative research. NY: Aldine de Gruyter (1967).
22. K. Charmaz, Constructing Grounded Theory: A Practical Guide Through Qualitative Analysis, Thousand Oaks: Sage (2006).

23. M.Q. Patton, Qualitative Research and Evaluation Method. Cal: Sage (2002).

24. Y.A. Wang, R.E. Pfitser, J. Travel Res. 47,1:84-93 (2008).

25. L. Knigge. M. Dope. Environ. Plan. 38,11:20212037.

26. C. Bailey, C. White, R. Pain, JSTOR, 31,2:169-178 (1999).

27. M. Hammersley, What's Wrong with Ethnography? London: Routledge (1992).

28. M. Van Manen, Researching lived experience: Human science for an action centered pedagogy. Ontario: The Althouse Press (1990).

29. D.T. Willingham, Cognition: The animal thinking NJ: Pearson (2007).

30. L. Fallon, L. Kriwoken, Tour. Manag. 24,3:289308 (2003).

31. D. Gursoy, D. Rutherford, Ann. Tour. Res. 31,3:495-516 (2004).

32. L. Nicholas. B. Thapa. Y.J. Ko. Ann. Tour. Res. 36,3:390-412.

33. M. Ribeiro, P. Pinto, S. João, Tour. Geogr., 15,4:654-679 (2013).

34. R. Ryan, E. Deci, Autonomy is no illusion: Selfdetermination theory and the empirical study of authenticity. awareness. and will. In J. Greenberg. S. L. Koole. T. Pyszczynski (Eds.). Handbook of Experimental existential psychology (p. 449-479). Guilford Press. (2004).

35. R. Ryan, E. Deci, Self-determination theory and the role of basic psychological needs in personality and the organization of behaviour. In: O. P. John. R. W. Robins. L. A. Pervin (Eds.). Handbook of personality: Theory and research (p. 654-678). The Guilford Press. (2008).

36. K. Kayat, Asia Pac. J. Tour. Res.7,2:19-27 (2002).

37. M. Heidegger, Being and Time. J. Macquarrie. E. Robinson. (Translators). New York: Harper \& Row (1962).

38. E.L. Deci, R. Koestner, R.M. Ryan, Psychol. Bull. 125,6:627-668 (1999).

39. Y.X. Xin Jin, W. Karin, L. Yang, Asia Pacific J. Tour. Res., 24,11:1066-1078 (2019).

40. L. Johnson, L. Freedman, Developing critical awareness at the middle level. Newark: International Reading Association (2005). 